\title{
Feasibility of single catheter intervention for multivessel coronary artery disease using transradial approach
}

\author{
Viabilidad de la intervención con un solo catéter para la enfermedad de la arteria \\ coronaria con múltiples vasos mediante abordaje transradial
}

\author{
Ricardo Allende-Carrera1*, Jesús A. Viana-Rojas², Adriana Saldierna-Galván³, Juan M. López-Quijano ${ }^{4}$, \\ José de J. Rivera-Arellano ${ }^{4}$, José L. Leiva-Pons ${ }^{4}$, and Jorge Carrillo-Calvillo ${ }^{4}$
}

${ }^{1}$ Departamento de Cardiología, Hospital de Especialidades Médicas de la Salud, San Luis Potosí; '2Departamento de Cardiología, Instituto Nacional de Ciencias Médicas y Nutrición "Salvador Zubirán", Mexico City; ${ }^{3}$ Centro Médico de Rioverde, Rioverde, San Luis Potosí; ${ }^{4}$ Departamento de Cardiología, Hospital Central "Dr. Ignacio Morones Prieto" San Luis Potosí, San Luis Potosí. México

\begin{abstract}
Objective: The objective of the study was to describe the feasibility of single catheter intervention using the transradial approach for percutaneous coronary intervention (PCI). Background: The transradial approach for $P C l s$ has fewer vascular events and complications and lower mortality rate. However, complications can result from forearm artery tortuosity, a longer learning curve and artery spasm that can complicate, delay and impede coronary artery interventions. The latter is usually exacerbated by the changing and manipulation of catheters. Methods: We performed a study using a single catheter on patients undergoing coronary assessment and treatment. Procedural outcomes including success, procedural time, bleeding, access site complications, and contrast used were all analyzed. Results: We included 327 patients, of whom $70 \%$ were male. The mean age was $63.3 \pm 11.1$ years, mean height was $165.9 \pm 7.7 \mathrm{~cm}$, mean weight was $73.3 \pm 11.3 \mathrm{~kg}$, and mean body index was $26.5 \pm 3.5 \mathrm{~kg} / \mathrm{m}^{2}$. Contrast use averaged $158.5 \pm 60.5 \mathrm{ml}$. Three vessels were treated in $3 \%$ of all cases, two vessels in $32 \%$, and one vessel in $65 \%$. Procedural success was achieved in $94.5 \%$ of the cases. A second catheter was required in 9 cases (2.7\%), and crossover to the femoral approach was performed in 9 cases (2.7\%) due to a lack of support, artery spasm, difficult anatomy, or the need for a larger catheter. Three complications were related to access, including a Class 2 hematoma that was treated conservatively with no further complications. Conclusions: Our study showed that using a single catheter to perform both diagnostic and therapeutic procedures has a higher success rate, lower spasm incidence, and fewer complications than reported in literature.
\end{abstract}

Key words: Percutaneous coronary intervention. Diagnostic catheterization. Percutaneous coronary intervention complications. Transradial approach. Mexico.

\section{Resumen}

Objetivo: Describir la factibilidad del uso de un solo catéter en el intervencionismo coronario percutáneo por vía transradial. Antecedentes: El abordaje transradial en las intervenciones coronarias ha mostrado menores eventos cardiovasculares y complicaciones, y menor mortalidad. Sin embargo, algunos eventos adversos pueden resultar por trotuosidad de las arterias

\section{Correspondence:}

*Ricardo Allende-Carrera

E-mail: ricardoallende@gmail.com
Available online: $30-10-2019$ Arch Cardiol Mex (Eng). 2019;89(2):147-153 www.archivoscardiologia.com 2604-7063 @ 2018 Instituto Nacional de Cardiología Ignacio Chávez. Published by Permanyer México SA de CV. This is an open access article under the CC BY-NC-ND license (http://creativecommons.org/licenses/by-nc-nd/4.0/). 
del brazo, curva de aprendizaje más larga o espasmo arterial que puede complicar, retardar o impedir la intervención coronaria. Ésta última es usualmente exacerbada por el intercambio de catéterres o la manipulación de los mismos. Métodos: Realizamos un studio utilizando un solo catéter en pacientes sometidos a coronariografía e intervención coronaria. Los desenlaces del procedimiento incluyendo éxito, tiempo de procedimiento, sangrado, complicaciones en el sitio de acceso y uso de medio de contraste fueron analizados. Resultados: Incluimos 327 pacientes, $70 \%$ de los cuales fueron varones. La edad promedio fue de $63.3 \pm 11.1$ años, la estatura promedio fue de $165.9 \pm 7.7 \mathrm{~cm}$, peso promedio de $73.3 \pm 11.3 \mathrm{~kg}$ y el índice de masa corporal promedio de $26.5 \pm 3.5 \mathrm{~kg} / \mathrm{m}^{2}$. El contraste utilizado promedio fue $158.5 \pm 60.5 \mathrm{ml}$. El total de vasos tratados fue de tres en $3 \%$ de los casos, dos en $32 \%$ de los casos y uno en $65 \%$. El éxito del procedimiento fue logrado en $94.5 \%$ de los pacientes No obstante, un Segundo catéter fue requerido en 9 intervenciones (2.7\%), y cambio en la vía de acceso fue realizado en 9 casos (2.7\%) por falta de apoyo, espasmo arterial, anatomía dificil o necesidad de un catéter de mayor lumen. Tres complicaciones asociadas al sitio de acceso incluyendo un hematoma clase 2 fueron registradas el cual se trató conservadoramente. Conclusiones: Nuestro estudio mostró que el uso de un catéter único para realizar tanto procedimientos diagnósticos como terapéuticos tiene una tasa de éxito mayor, con menor incidencia de espasmo y complicaciones reportadas en la literatura.

Palabras clave: Intervención coronaria percutánea. Cateterismo diagnóstico. Complicaciones en intervención coronaria percutánea. Cateterismo transradial. México.

\section{Introduction}

The transradial approach for percutaneous coronary interventions ( $\mathrm{PCls}$ ) has shown some benefits compared to the transfemoral approach ${ }^{1}$. These include fewer vascular events ${ }^{2}$, fewer bleeding complications, lower mortality, and earlier ambulation ${ }^{3,4}$. These factors favor the transradial approach over the transfemoral approach ${ }^{5}$. However, some factors make the transradial approach a less favorable option for treating coronary arteries. Such factors include: the tortuosity of arm and forearm arteries, a longer learning curve and artery spasms that can complicate, delay and impede coronary artery interventions $^{6}$. The latter complication is usually caused by the changing and manipulation of catheters. Typically, both femoral and transradial access requires one catheter to assess each coronary artery and another to treat the affected vessel. Nevertheless, models have shown that femoral catheters used in the transradial approach have a very different catheter landing on the aortic root compared to the transfemoral approach. To this effect, catheter exchange has been related to increased procedural time, contrast use, bleeding, and radial artery spasm? ${ }^{7}$.

We performed a study to evaluate the feasibility of a single catheter to assess and treat coronary arteries.

\section{Methods}

\section{Study population}

We included 327 consecutive patients undergoing coronary assessment and treatment for whom a single catheter was used for the entire procedure. Patients were enrolled between January 2014 and December 2015. An Ikari left catheter was used (Terumo Medical Corporation, Tokyo, Japan). For patients shorter than $5^{\prime} 6$ ", the lkari $3.5 \mathrm{~cm}$ curve left catheter was used. For patients over $5^{\prime} 6^{\prime \prime}$, the $4 \mathrm{~cm}$ curve catheter was used (Fig. 1).

\section{Study endpoints and definitions}

The primary endpoint was the rate of procedural success and complications. Complications were one or more of the following:

1. Crossover determined as the failure of a single catheter to perform both the angiography and angioplasty.

2. Access site-related injury defined as dissection, stenosis, perforation, rupture, arteriovenous fistulae, pseudoaneurysm, hematoma, compartment syndrome or hemostatic device failure documented either clinically or by imaging studies ${ }^{8}$.

3. Artery spasm defined as an increase of vascular tone resulting in a difficulty in manipulating the catheter accompanied by pain in the arm of the forearm of the patient. It was considered significant when it prevented the operators from continuing or when the patient suffered considerable pain exceeding five on the verbal numeric scale ${ }^{9}$.

\section{Procedural considerations}

All patients agreed to participate in the study and signed an informed consent form before the procedure whenever possible or after the procedure in emergent cases. 


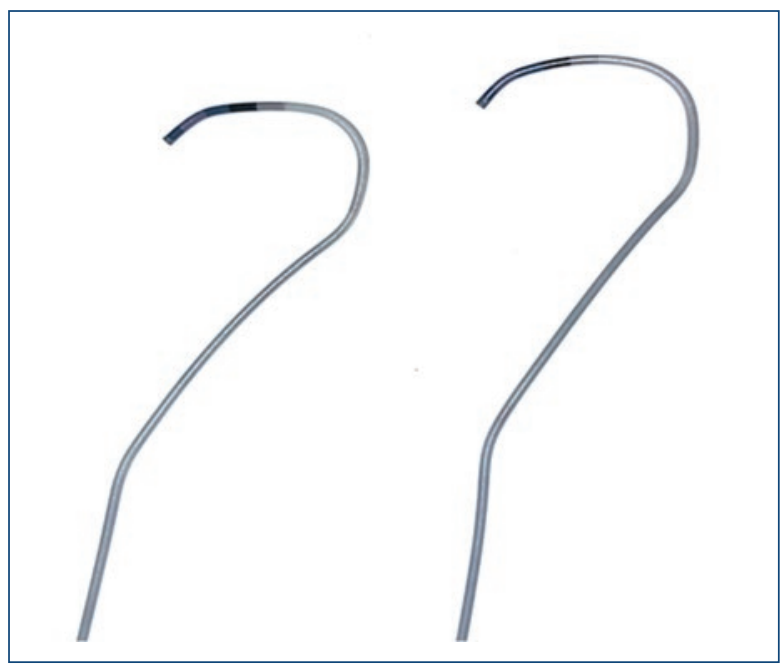

Figure 1. Image of two Ikari catheters. On the left is the $3.5 \mathrm{~cm}$ curve and on the right is the $4 \mathrm{~cm}$ curve.

All lesions were evaluated by a group of four interventional cardiologists and were considered significant according to the ACC/AHA/SCAI guidelines ${ }^{10,11}$.

\section{Catheter manipulation technique}

For all cases, a 6- French Ikari Left catheter was used. The catheter was connected to pressure and contrast lines through a " $Y$ " connector. A 0.035-inch J-tipped $110-\mathrm{cm}$ guidewire was directed into the catheter through the "Y" connector, and the whole system was flushed outside the patient with heparinized saline. The catheter was then inserted through the introducer sheath and advanced through the forearm and arm arteries to the aortic root with the "J" Guidewire. The J Guidewire was then retracted into the catheter. For stable elective patients, angiography was started near the non-affected artery. If the affected artery was unknown or if multiple vascular lesions were suspected, angiography was initiated on the left coronary artery (LCA). In the cases of acute coronary syndromes, the procedure was started with angioplasty of the suspected artery.

Left artery cannulation was performed by pushing the $\mathrm{J}$-Guidewire to the aortic valves. Then, the catheter was brought down to the aortic valves, and the guidewire was retracted into the catheter. Subsequently, the catheter was retracted, directed toward the left coronary cusp and then pushed down to bend the curve just to the point necessary to cannulate the left coronary ostium.

Right artery cannulation was performed by pushing the J-guidewire down toward the aortic valves. The

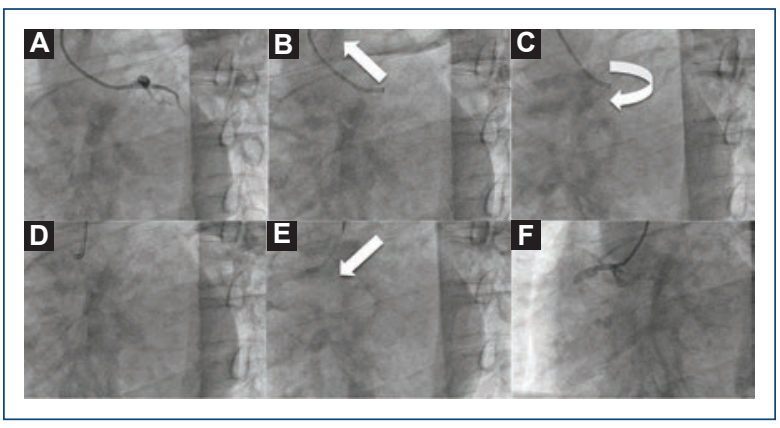

Figure 2. Image which shows the left and right coronary artery cannulation technique. (A-F). Cannulation of the left coronary artery (LCA) which shows contrast injection into the LCA system (A), retraction of the catheter to the ascending aorta to disengage the LCA (B), clockwise $90^{\circ}$ rotation of the catheter to change the tip of the catheter to the contralateral sinus (C), stabilization of the catheter on the aorta will allow continuing with changing of the sinus (D), advancement and simultaneous $90^{\circ}$ rotation of the catheter down to the aortic root and the right coronary ostium will place the catheter correctly (E), cannulation and contrast injection into the right coronary artery (F).

catheter was then pushed down and turned clockwise toward the right coronary cusp. Then, the Guidewire was retracted while pushing the catheter at the same time to cannulate the right coronary artery (RCA) (Fig. 2).

\section{Access site evaluation}

Clinical follow-up and access site evaluation were performed daily during hospitalization and at discharge. A detailed examination of the puncture area was performed looking for complications such as bleeding, hematoma, ecchymosis, loss of arterial pulse, cyanosis, paleness, or any other change. All changes compared to baseline were registered.

\section{Statistical analysis}

Demographic variables such as sex, age, height, and weight were obtained. Diagnosis, clinical presentation, and treated artery information were also collected. Outcomes such as procedural success, arterial spasm, bleeding, and complications were analyzed.

Continuous variables are presented as the mean (standard deviation) or median $\left(25^{\text {th }}-75^{\text {th }}\right.$ interquartile range) depending on variable distribution. Categorical variables were analyzed by frequency distribution represented as percentages. Analyses between affected vessels were performed with ANOVA. $p<0.05$ was 
Table 1. Demographics, clinical and procedural characteristics of patients

\begin{tabular}{|l|c|}
\hline & $\mathbf{n}(\%)$ \\
\hline Male sex & $234(70)$ \\
\hline Age (years) & $63.3 \pm 11.1$ \\
\hline Body mass index $\left(\mathrm{Kg} / \mathrm{m}^{2}\right)$ & $26.5 \pm 3.5$ \\
\hline Contrast use & $158.5 \pm 60.5 \mathrm{ml}$ \\
\hline Three vessels treated $(\%)$ & 3 \\
\hline Two vessels treated $(\%)$ & 32 \\
\hline One vessel treated $(\%)$ & 65 \\
\hline Single catheter success $(\%)$ & 95.4 \\
\hline
\end{tabular}

considered statistically significant. All analyses were conducted using the statistical package SPSS version 19 (IBM, Armonk, NY, USA).

\section{Results}

\section{Patients and baseline characteristics}

We analyzed 327 consecutive patients who underwent coronary artery assessment and intervention using the transradial approach. Baseline and procedural characteristics of the study population are shown in Table 1. The male sex was predominant, with $70 \%$ of all patients (234 males/93 females). The mean age was $63.3 \pm 11.1$ years. Anthropometric measures revealed a mean height of $165.9 \pm 7.7 \mathrm{~cm}$, mean weight of $73.3 \pm 11.3 \mathrm{~kg}$, and mean body index of $26.5 \pm$ $3.5 \mathrm{~kg} / \mathrm{m}^{2}$. Contrast use was $158.5 \pm 60.5 \mathrm{ml}$. Three vessels were treated in $3 \%$ of all cases, two vessels in $32 \%$, and one in $65 \%$ of all cases. Procedural success was achieved in $94.5 \%$ of all cases performed with a single catheter using the transradial approach. A second catheter was required in 9 cases $(2.7 \%)$, and crossover to the femoral approach was performed in 9 cases $(2.7 \%)$ due to lack of support, artery spasm, difficult anatomy, or the need of a larger catheter. Three complications were related to access, including a Class 2 hematoma that was treated conservatively with no further complications. Specific analysis of the treated vessels and ipsilateral and contralateral arteries was performed, with no significant difference observed with fluoroscopy or contrast use among left anterior descending (LAD) + RCA, LAD + circumflex
Table 2. Clinical and procedural characteristics between culprit vessel

\begin{tabular}{|l|c|c|c|c|}
\hline & LAD + RCA & LAD $+\mathbf{C x}$ & $\mathbf{R C A}+\mathbf{C x}$ & $\mathbf{p}$ value \\
\hline Age & $64 \pm 12$ & $66 \pm 10$ & $66 \pm 9$ & 0.92 \\
\hline Fluoroscopy & $17 \pm 9$ & $21 \pm 12$ & $24 \pm 16$ & 0.63 \\
\hline Contrast (ml) & $163 \pm 29$ & $175 \pm 37$ & $187 \pm 37$ & 0.48 \\
\hline
\end{tabular}

LAD: Left anterior descending, RCA: Right coronary artery, Cx: Circumflex artery

Table 3. Clinical and procedural characteristics of failed procedures

\begin{tabular}{|l|c|}
\hline Age (years) & $71 \pm 12.1$ \\
\hline Weight $(\mathrm{kg})$ & $73.5 \pm 12.0$ \\
\hline Height $(\mathrm{cm})$ & $163.5 \pm 6.7$ \\
\hline BMI $\left(\mathrm{kg} / \mathrm{m}^{2}\right)$ & $27.7 \pm 3.4$ \\
\hline Fluoroscopy $(\mathrm{min})$ & $10.1 \pm 5.2$ \\
\hline Contrast $(\mathrm{ml})$ & $186 \pm 83.7$ \\
\hline
\end{tabular}

artery $(C x)$ or RCA $+C x$ (Table 2). Analysis was also performed in cases of failure to complete the procedure with a single catheter.

\section{Baseline and procedural characteristics among failed procedures with crossover or two-catheter use}

A total of 18 patients required two-catheter use or crossover to femoral access. Reasons for two-catheter use included lack of support in nine patients and unfavorable coronary anatomy for the catheter on the remaining six patients. 12 of the 15 patients were male $(80 \%)$ and their mean age was $71 \pm 12.1$ years. Anthropometric characteristics included a mean weight of $73.5 \pm 12.9 \mathrm{~kg}$, mean height of $163.5 \pm 6.7 \mathrm{~cm}$, and mean body mass index of $27.7 \pm 3.4 \mathrm{~kg} / \mathrm{m}^{2}$. Procedural characteristics included a mean fluoroscopy time of $10.1 \pm 5.2$ minutes. The mean contrast volume used was $186 \pm 83.7 \mathrm{ml}$. The procedural context was ST-segment elevation myocardial infarction (STEMI) in 9 of 15 patients (60\%). $50 \%$ of the patients required three-vessel interventions and the remaining $50 \%$ required two-vessel intervention. Procedural success with a single catheter was achieved in 312 of the 327 patients (95.4\%) (Table 3). 


\section{Discussion}

Coronary procedures usually require different catheters to evaluate, measure, and treat different lesions. Femoral access may facilitate backup, catheter stability, and adequate control of the lesion.

Most of the problems reported when using transradial access were an inability to access radial artery, arterial spasm, anatomical limitations, failure to cannulate the target vessel, and inadequate catheter support ${ }^{12}$.

The incidence of crossover due to spasm or anatomy abnormalities is reported to be approximately $3.9 \%$. Some factors that cause an increase of radial artery spasm include anatomical abnormalities, young age, female gender, therapeutic procedures, pain, procedural time, and the use of three or more catheters ${ }^{13}$.

Dehghani et al. showed a procedural failure of $4.7 \%$ during 2,100 transradial procedures with a total of 1.2 \pm 0.6 catheters used for successful procedures versus $1.4 \pm 0.6$ catheters for failed procedures when treating the RCA and $1.2 \pm 0.6$ catheters for successful procedures versus $1.6 \pm 1.0$ catheters for failed procedures when treating the LCA. During transradial failures, operators used six and seven catheters for RCA and LCA, respectively, before crossover to $\mathrm{TF}^{14}$.

Some factors have been studied associated with $\mathrm{PCl}$ failure. They have been described as a failure of arterial access, inability to advance the catheter into the ascending aorta and inability to complete the $\mathrm{PCl}$ due to lack of guide support. $13 \%$ of the cases had an inadequate arterial puncture. Among cases of failure to advance the catheter into the ascending aorta, $34 \%$ of patients had radial artery spasm, $10 \%$ had radial artery loop or tortuosity, $6 \%$ had radial artery dissection, and $1 \%$ had radial artery stenosis. Failure to complete PCI due to lack of guide support was due to subclavian tortuosity in $18 \%$ and inadequate guide backup support in $17 \%$.

The importance of catheter selection may directly be related to appropriate support, adequate access to coronary ostium, and procedural success ${ }^{15}$.

An additional backup catheter (Voda, XB, and EBU) may improve procedural success with different modalities. However, there have been limitations with treating left main lesions, short left main with ostial circumflex lesions and right coronary lesions (Fig. 3). The Amplatz right catheter facilitates ostial access to right proximal, mid-, or distal coronary lesions. However, when significant tortuosity is present, it may be difficult to stabilize or advance the catheter. Furthermore, it does not offer

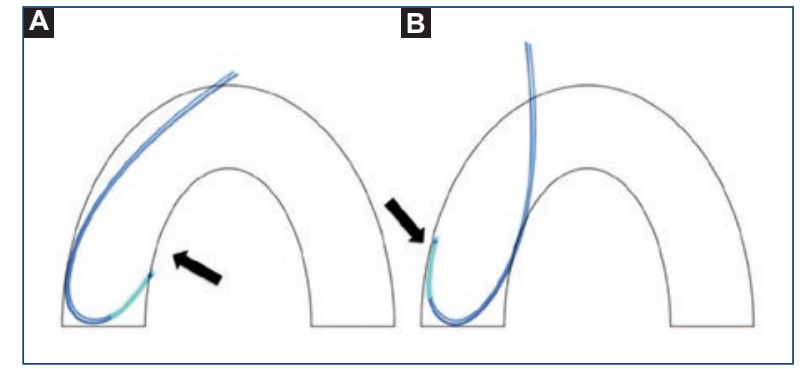

Figure 3. Diagram of the additional backup catheters and their contact angles.

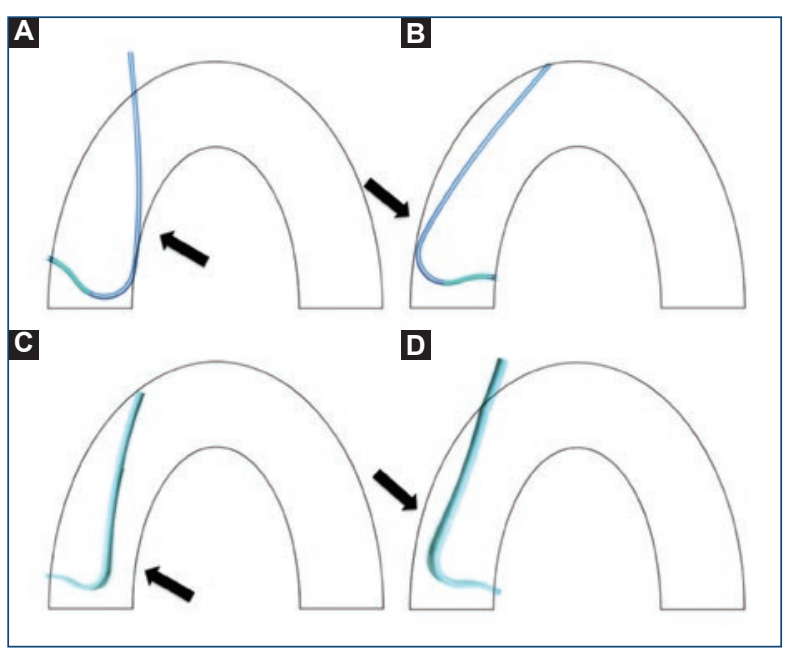

Figure 4. Diagram of the Amplatz left catheter in the right coronary ostium (A), Amplatz left catheter in the left coronary ostium. Note the low one-point support on the contralateral wall. (B) Right Amplatz catheter in the on the right coronary ostium. Note the absence of support on the contralateral wall. (C) Right Amplatz catheter in the left coronary ostium. Note the lack of support on the contralateral wall when performed by the transradial approach (D).

adequate support, stability or control when treating the left coronary system. The Amplatz left catheter may provide good support and stability to the RCA and may ease balloon and stent placement. Nevertheless, when treating proximal and ostial lesions, the complexity might increase. In addition, it does not offer good support for interventions of the LCA through the transfemoral approach (Figs 4A-4D).

The Judkins traditional JL and JR catheters have good curvature and support for the femoral approach but do not transmit the same force when used in the transradial approach (Figs 5A-5D). 


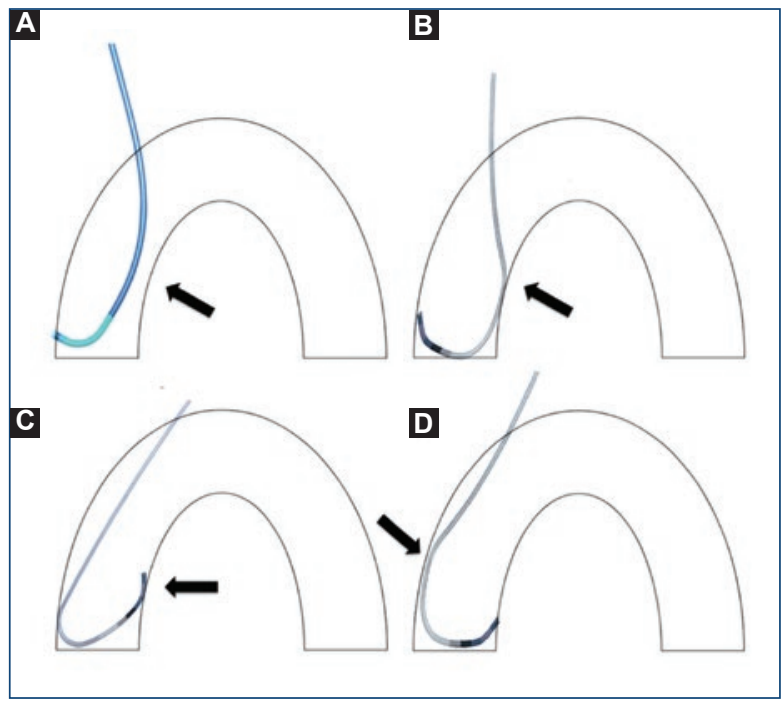

Figure 5. Diagram of the Judkins right coronary catheter in the right coronary ostium. Note the lack of support on the contralateral wall (A). Ikari left catheter in the right coronary ostium (B). Judkins left coronary catheter in the left coronary ostium. Note the absence of a landing zone on the ostium (C). Ikari left catheter on the left coronary ostium. Note the support on the contralateral wall when performed using the transradial approach (D).

\section{Feasibility of single-catheter use for the right and LCAs}

Procedural success requires both optimal stent profile and guidewire support. Some principles of guide catheter selection are necessary for successful PCl. Backup support and coaxial engagement are two features of catheter properties necessary for every procedure. Ikari showed that the Ikari $L$ catheter has some modifications from the Judkins $L$ catheter that may facilitate procedures:

1. A shorter length between the third and fourth angles

2. Longer length between the second and first angles

3. A first angle to fit the brachiocephalic artery.

As shown in Fig. 5, these properties improve backup support for the LCA. When used in the RCA, it may be used in a passive way as with the Judkins $R$. catheter. However, when more force is necessary, the contralateral aortic wall will increase backup support not provided by any other catheters as shown during in vitro studies ${ }^{16}$.

\section{Benefits of single-catheter use for right and LCAs}

Operator dexterity and learning curve have some influence on rates of procedural success, radial spasm, artery dissection, procedural time, and contrast use. However, single-catheter use shows some benefits over the selection of two or more catheters.

For STEMI patients, transradial access has fewer bleeding complications.

Both the total and procedural times are minimized, thus eliminating the catheter exchange time. Therefore, door-to-balloon time is shortened. Fluoroscopy time is reduced because the tip of the catheter always remains over the valvular plane and only clockwise rotation is needed to place the catheter in the coronary ostium.

Radial artery spasm is diminished because the arterial path is minimally manipulated.

Bleeding is low because the system is always closed and no catheter exchange is needed. Finally, after the procedure, it has the benefits of radial access.

\section{Conclusions}

Procedural success is achieved with a single catheter in $94.5 \%$ of all cases. It is a feasible technique that provides appropriate catheter support, a low complication rate, low procedural time, and a low bleeding rate with reduced cost.

\section{Conflicts of interest}

None.

\section{Funding}

None.

\section{Acknowledgments}

Authors would like to thank Ms. Teresa Delgadillo for the given support to complete this protocol.

\section{Ethical disclosures}

Protection of human and animal subjects. The authors declare that no experiments were performed on humans or animals for this study.

Confidentiality of data. The authors declare that no patient data appear in this article.

Right to privacy and informed consent. The authors declare that no patient data appear in this article.

\section{References}

1. Kiemeneij F, Laarman GJ, de Melker E. Transradial artery coronary angioplasty. Am Heart J. 1995;129:1-7. 
2. Kiemeneij F, Laarman GJ, Odekerken D, Slagboom T, van der Wieken R. A randomized comparison of percutaneous transluminal coronary angioplasty by the radial, brachial and femoral approaches: the access study. J Am Coll Cardiol. 1997;29:1269-75.

3. Wu CJ, Lo PH, Chang KC, et al. Transradial coronary angiography and angioplasty in chinese patients. Cathet Cardiovasc Diagn. 1997;40:159-63.

4. Hildick-Smith DJ, Walsh JT, Lowe MD, Petch MC. Coronary angiography in the fully anticoagulated patient: the transradial route is successful and safe. Catheter Cardiovasc Interv. 2003;58:8-10.

5. Azzi $\mathrm{N}$. The radial approach in the cardiac catheterization laboratory: is it meant to become the gold standard? J Med Liban. 2011:59:227-32.

6. Salgado Fernández J, Calviño Santos R, Vázquez Rodríguez JM, et al. Transradial approach to coronary angiography and angioplasty: initial experience and learning curve. Rev Esp Cardiol. 2003;56:152-9.

7. Hildick-Smith DJ, Walsh JT, Lowe MD, Shapiro LM, Petch MC. Transradial coronary angiography in patients with contraindications to the femora approach: an analysis of 500 cases. Catheter Cardiovasc Interv. 2004;61:60-6.

8. Kikkert WJ, van Geloven N, van der Laan MH, et al. The prognostic value of bleeding academic research consortium (BARC)-defined bleeding complications in ST-segment elevation myocardial infarction: a comparison with the TIMI (Thrombolysis in myocardial infarction), GUSTO (Global utilization of streptokinase and tissue plasminogen activator for occluded coronary arteries), and ISTH (International society on thrombosis and haemostasis) bleeding classifications. J Am Coll Cardiol. 2014;63:1866-75

9. Holdgate A, Asha S, Craig J, Thompson J. Comparison of a verbal numeric rating scale with the visual analogue scale for the measurement of acute pain. Emerg Med (Fremantle). 2003;15:441-6.
10. Fihn SD, Blankenship JC, Alexander KP, et al. 2014 ACC/AHA/AATS/ PCNA/SCAI/STS focused update of the guideline for the diagnosis and management of patients with stable ischemic heart disease: a report of the American college of cardiology/American heart association task force on practice guidelines, and the American association for thoracic surgery, preventive cardiovascular nurses association, society for cardiovascular angiography and interventions, and society of thoracic surgeons. Circulation. 2014;130:1749-67.

11. Wessler JD, Stant J, Duru S, Rabbani L, Kirtane AJ. Updates to the ACCF/AHA and ESC STEMI and NSTEMI guidelines: putting guidelines into clinical practice. Am J Cardiol. 2015;115:23A-8.

12. Agostoni P, Biondi-Zoccai GG, de Benedictis ML, et al. Radial versus femoral approach for percutaneous coronary diagnostic and interventional procedures; Systematic overview and meta-analysis of randomized trials. J Am Coll Cardiol. 2004:44:349-56.

13. Ruiz-Salmerón RJ, Mora R, Vélez-Gimón M, et al. Radial artery spasm in transradial cardiac catheterization. Assessment of factors related to its occurrence, and of its consequences during follow-up. Rev Esp Cardiol. 2005;58:504-11.

14. Dehghani P, Mohammad A, Bajaj R, et al. Mechanism and predictors of failed transradial approach for percutaneous coronary interventions. JACC Cardiovasc Interv. 2009;2:1057-64.

15. Valsecchi $O$, Vassileva A, Musumeci $G$, et al. Failure of transradial approach during coronary interventions: anatomic considerations. Catheter Cardiovasc Interv. 2006;67:870-8.

16. Ikari Y. Long-term experience using the ikari guide catheter for radial PCl. J Interv Cardiol. 2013;21:36-41. 